\title{
Expressions of Criticality in Expert and Student Writing: A Corpus Contrastive Analysis of Literature Reviews
}

\author{
Muna Liyana Mohamad Tarmizi ${ }^{1}$, Anealka Aziz Hussin ${ }^{2}$ \\ ${ }^{1}$ Akademi Pegajian Bahasa \\ Universiti Teknologi MARA (UiTM) \\ muna4566@uitm.edu.my \\ ${ }^{2}$ Akademi Pegajian Bahasa \\ Universiti Teknologi MARA (UiTM) \\ anealka@uitm.edu.my \\ Article history: \\ Accepted: 23 July 2021 \\ Published: 31 July 2021
}

Received: 8 February 2021

\begin{abstract}
Literature review in academic writing plays an integral role in demonstrating writers' knowledge about a field of study as well as in informing the influential researchers and research groups in the field. More importantly, writers are expected to critically analyze previous studies related to their topic. Despite its importance to the academic text, student writers find it challenging to establish a critical stance and to provide evaluative judgment when reviewing the literature. This paper presents a contrastive analysis of expert and student writers' expressions of criticality in literature review sections. The study first determined the types of critical expressions used by the two groups of writers and then, compared the similarities and differences of the use of criticality expressions based on Hyland's Interactional Model of Academic Discourse. A corpus-based approach was adopted to identify the most common expressions of criticality used by these two groups of writers which were selected using a purposive sampling technique. WordSmith Tools was used to analyze the samples. The findings revealed that, unlike the expert writers, the student writers prefer to use hedges and boosters to express criticality and the evaluations sounded more like reporting rather than analyzing and synthesizing the resources critically. Results from this study are beneficial for constructing pedagogical instructions and guidelines for student writers in their critical analysis of the literature review.
\end{abstract}

Keywords: expressions of criticality, literature reviews, critical analyses, corpus linguistics, learner corpus research 
Muna Liyana Mohamad Tarmizi, Anealka Aziz Hussin

Expressions of Criticality in Expert and Student Writing: A Corpus Contrastive Analysis of Literature Reviews

\subsection{Introduction}

Hyland and Diani (2009) have classified texts and any part of texts which are written with specific purpose to evaluate research, texts, and the contributions of academics as review genres. These texts comprise book reviews, book review articles, book blurbs, review articles and literature reviews. As a chapter, literature review is a required component in any thesis or dissertation, and it also has been included in the writing of research articles (Hei \& David, 2015). According to Fernandez (2019), literature review can be defined as a summary and evaluation of the relevant body of work like academic articles, published conference papers, book chapters or even the entire book. From the literature review, writers can provide insights on gaps that need to be addressed and explain the significance of the current study by connecting previous studies to the present study and critically evaluating previous works.

A literature review is also written for a main purpose to justify the value of a research, and to distinguish what has been done from what needs to be done which further explains the necessity of a particular study to be carried out (Hart, 1998 and Kwan, 2006). Fernandez (2019) summarizes five (5) key outcomes of a literature review which include:

a. To demonstrate writer's knowledge about the prior and current work relevant to the research

b. To identify research gaps by finding out issues that have not been examined or have been mis-studied

c. To provide good foundation for writer to develop specific research questions

d. To position an empirical article or thesis with respect to prior literature and

e. To develop new theory

Based on these significant purposes and outcomes, it can be said that literature review is important as a foundation of any research project because it sets the context of the study and it examines critically the research methods used in existing literature as well as justifies decisions made for the study. Looking at its critical roles, literature review needs to be well written so that it can fully reflect a research's potential.

As emphasized by many authors and researchers, a good literature review does not only contain a summary on collections of related studies pertinent to the research, but most importantly, it should include author's critical evaluation and personalized voice (Akindele, 2008; Bruce, 2014; Shahsavar and Kourepaz, 2020). In other words, writers are expected to be able to analyze, synthesize and evaluate arguments and evidence and exert their criticality confidently and appropriately when expressing their opinions, emotions and attitudes towards certain claims or propositions.

Despite the given criteria of a good review of literature, expressing criticality in this genre has been seen as a big challenge especially for student writers (Shahzavar \& Kourepaz, 2020). The term criticality was coined by Bruce (2014) to describe evaluative judgments made by writers within any field of human activity about some aspect, object, or behavior of that field. In the last few decades, criticality in academic writing has 
been approached from various angles using different terms like evaluation (Geng \& Wharton, 2016; Tucker, 2003; Xie, 2016), stance (Biber, 2006; Charles, 2006; Crosthwaite, Cheung \& Jiang, 2017; Hyland, 2005; Jiang \& Hyland, 2015), and also voice (Escobar \& Fernández, 2018; Lores-Sanz, 2011; Matsuda \& Jeffery, 2012; Nelson \& Castello, 2012) to show writer's viewpoints, emotions, attitudes, and positions towards certain entities or propositions. All of these are elements of critical evaluation and pertinent for effective literature review writing.

\subsection{Problem Statement}

A literature review is valuable in highlighting research gaps, generating new research hypotheses, and most importantly to justify why one's research needs to be conducted (Kwan, 2006; Kwan, Chan \& Lam, 2012). Writers are expected to be able to show criticality when evaluating theories, claims, and propositions relevant to the topic being discussed. However, providing evaluative judgment or expressing criticality has been a great concern by researchers and various other stakeholders including the student writers themselves.

According to Hidalgo and Funderburk Razo (2014), one of the major difficulties faced by students is the need for evaluating sources that support the research in their writing. Osman (2016) stresses that postgraduate students usually face problems in putting forward their opinion, arguing their points, or agreeing with existing ideas. Based on a recent study too, it was found that even proficient students were not able to synthesize, critique, or explain the literature in their writing (Shahzavar \& Kourepaz, 2020). Therefore, looking at these issues, how student writers express criticality when reviewing the literature in their thesis writing is a topic worth studying.

In addition to that, Lee and Chen (2009) consider research articles as model for writings that student writers should look up for. As an important form of research reporting text, research articles written by a researcher, or a group of researchers involves a thorough proof-reading, peer review, and editorial process before it is published in a peer-reviewed scholarly journal. Due to the meticulous process of getting a research article published, these writers have been considered as expert writers (Lee \& Chen, 2009). Considering the significant roles of a literature review and research articles as a writing model, it is important to explore how expert writers express criticality when reviewing the literature.

Therefore, the current study aims to:

1. identify the expressions of criticality used by expert writers when reviewing the literature

2. identify the expressions of criticality used by student writers when reviewing the literature

3. compare the similarities and differences on the expressions of criticality used by student writers and expert writers when reviewing the literature 
Muna Liyana Mohamad Tarmizi, Anealka Aziz Hussin

Expressions of Criticality in Expert and Student Writing: A Corpus Contrastive Analysis of Literature Reviews

\subsection{Literature Review}

In this section, concepts related to the study are discussed including various definitions and aspects of criticality as well as linguistic features to express criticality.

\subsection{Criticality}

There are several ways criticality has been defined in the extant literature. Bruce (2014) explains that criticality is a form of evaluative judgment where writers can establish a personalized and critical voice in writing. Several related terms include hedging (e.g., Hyland, 1998), evaluation (e.g., Thompson \& Hunston, 2000), appraisal (e.g., Martin, 2000), and stance (e.g. Biber \& Finegan, 1989) which basically explain the linguistic mechanism that expresses a speaker or writer's personal attitudes and emotions as well as evaluations on status of knowledge (Gray \& Biber, 2012).

Biber and Finegan (1989) use the term stance to refer to expressions of personal feelings and assessments including attitudes that a speaker has about certain information and the perspective the speaker is taking. Another term is evaluation which involves the speaker or writer's judgment of a proposition or entity in terms of its positivity, certainty, expectedness, and importance (Thompson \& Hunston, 2000). Elsewhere, this construct is referred to as appraisal (Martin \& White, 2005) which involves the traditional concept of affect and epistemic modality that encompasses attitude, engagement, and graduation.

In another approach, Hyland (1998) highlights the term hedging which refers to markers that limit the writer's commitment to a proposition and boosting referring to expressions indicating a high degree of certainty towards a proposition. In more recent work, he put forth an overall concept of stance related to academic writing which focused on the writer's stance and engagement through elements of hedging, boosting, attitude markers, and presence (Hyland, 2005).

Despite the range of terms being used, two main concepts have been identified as the foundation to investigate criticality or stance in the previous studies: evidentiality and affect (Gray \& Biber, 2012). Evidentiality refers to the status of the knowledge contain in propositions (Gray \& Biber, 2012). This can be investigated by evaluating the degree of reliability of knowledge; by specifying the mode of knowledge and by marking the contrast between knowledge and expectation (Barton, 1993).

Affect, on the other hand, involves a broad range of personal and professional attitudes towards what is said, including perspective, and beliefs (Hyland, 2005). Different from evidentiality, affect markers express personal feelings, emotions, and attitudes rather than evaluations of knowledge (Gray \& Biber, 2012).

Drawing from these foundational concepts and inter-related terminologies, this study takes a broad definition of criticality as careful evaluation and judgment as well as a writer's personal and professional 
assessments, opinions, and commitments towards the entities or propositions that are explicitly or implicitly encoded in the written academic texts.

\subsection{Linguistic Devices}

Writers can express their critical evaluation - personal or professional emotion, attitude, and level of commitment on a particular claim, through the use of some grammatical features or linguistic devices. Several models and criteria have been developed to understand how writers express their opinions, stance and evaluation of ideas being discussed in the texts. From the various models and taxonomies available, there are few prominent models being used in many studies which include Hyland's (2005) Academic Interaction Model, Biber's Lexico-grammatical Devices (2006) and Martin and Rose's (2003) Appraisal Theory (see Table 1) to investigate expressions of criticality or stance.

Table 1 Summary of Prominent Models and Taxonomies for Expressions of Criticality or Stance

\begin{tabular}{|c|c|c|}
\hline $\begin{array}{c}\text { Academic Interaction } \\
\text { (Hyland,2000) }\end{array}$ & $\begin{array}{l}\text { Lexico-grammatical Devices } \\
\text { (Biber, 2006) } \\
\end{array}$ & $\begin{array}{c}\text { Appraisal Theory } \\
\text { (Martin and Rose, 2003) } \\
\end{array}$ \\
\hline Stance & Modal and Semi modal verbs & Engagement \\
\hline Hedges & Possibility/ permission/ ability (may, might, could..) & Haterogloss \\
\hline Boosters & Necessity/ obligation (must, should, ought to) & - $\quad$ Contraction \\
\hline Attitude Markers & & disclaim) \\
\hline Self- Mention & $\begin{array}{l}\text { Adverbs } \\
\text { Epistemic }\end{array}$ & - $\quad$ Expansion (attribute, entertain) \\
\hline Engagement & Certainty (actually, certainly) & Attitude \\
\hline Reader Pronouns & Likelihood (perhaps, possibly) & - $\quad$ Appreciation \\
\hline Directives & Attitude (amazingly, importantly) & reaction, composition) \\
\hline Questions & Style (according to, generally, typically) & \\
\hline - $\quad$ Shared & & Graduation \\
\hline Knowledge & Compliment clauses: stance verb, adjectives and nouns & - Force (intensity, quantity, \\
\hline \multirow[t]{6}{*}{ - $\quad$ Personal asides } & Stance verb + that clause & enhancement) \\
\hline & Stance verb + to clause & - $\quad$ Focus (Valuer as entity focused) \\
\hline & Stance adj + that clause & \\
\hline & Stance adj + to clause & \\
\hline & Stance noun + that clause & \\
\hline & Stance noun + to clause: failure, ability & \\
\hline
\end{tabular}

In his Lexico-grammatical framework, Biber (2006) proposes three main elements for the analysis of stance which include: Modal and semi-modal verbs (possibility, necessity, and prediction), stance adverbs (epistemic certainty and likelihood, attitude, and style), and complement clauses which are controlled by stance verbs, adjectives, or nouns. Whereas the appraisal framework organizes evaluation in three main semantic systems or domains: engagement, attitude, and graduation (Oteiza, 2017).

Hyland's (2005) extensive framework in this area covers how academics use language to express their stance (stance) and engage with their readers (engagement). Since the focus of this study is to identify how writers express criticality, only elements with writers-oriented features are examined. Hyland's stance in the 
Expressions of Criticality in Expert and Student Writing: A Corpus Contrastive Analysis of Literature Reviews Academic Interaction model has been determined as one of the research instruments. According to Hyland, there are four main features of stance:

1. Hedges

2. Boosters

3. Attitude Markers

4. Self-mentions

\subsubsection{Hedges}

Hedges are used to indicate writers' level of commitment to a proposition which allows certain information to be presented as an opinion rather than fact (Hyland, 2005). Devices like possible, perhaps, and might are used by writers to hedge and at the same time could also indicate a certain level of modesty or respect for other writers' or expertise's views (Hyland, 2005).

\subsubsection{Boosters}

Different from hedges, boosters are used by writers to express their certainty in what they state and to mark involvement with the topic being discussed (Hyland, 2005). Words like clearly, obviously and demonstrate, allow writers to present their work with assurance and are usually used by writers to stress shared information, group membership, and engagement with readers (Hyland, 2005).

\subsubsection{Attitude Markers}

Attitude markers indicate writers' attitude towards propositions such as surprise, agreement, importance, frustration, and so on (Hyland, 2005). This can be expressed or signaled by attitude verbs (agree, prefer), sentence adverbs (unfortunately, hopefully), and adjectives (appropriate, remarkable).

\subsubsection{Self-Mentions}

Self-mentions refer to the use of first-person pronouns $(I$, we) and possessive adjectives (my, our) to present propositional, affective, and interpersonal information. Self-mentions can distinguish writers' role in the research whether they want to downplay their personal role and highlight the phenomenon under research or to establish their role in the study.

\subsection{Methodology}

This section explains the research design, sampling method as well as instruments used for the study. Procedures for data collection and data analysis are also presented. 
International Journal of Modern Languages and Applied Linguistics e-ISSN: 2600-7266

\subsection{Research Design}

This study involved two sets of corpora of literature reviews written by expert writers and student writers. Both corpora were developed to fit the objectives of the study. The first corpus, the Expert Literature Review Corpus (ELRC) is the reference corpus, consists of journal articles taken from a variety of high-ranking linguistics and applied linguistics journals (e.g., English for Academic Purposes, Language and Communication and Applied Linguistics). Whereas the second corpus is Malaysian Literature Review Corpus (MLRC) corpus is the target corpus, consisting of literature review chapters from UiTM applied linguistics master theses.

A corpus-based approach was used to identify the most common expressions of criticality used by the two groups of writers. For this study, a list of words which were used to express criticality under four (4) features of stance based on Hyland's (2005) Academic Interaction model namely hedges, boosters, attitude markers, and self-mention was adopted from Dobakhti (2011).

Each corpus was analyzed using detailed consistency analysis and concordance software from WordSmith Tools (Scott, 2012). Detailed consistency analysis enabled the researchers to see the occurrence of words that are used to express criticality in the whole corpus as well as in each unit. The analysis of the list helped the researchers to identify linguistic devices from the four (4) elements of stance used by learners and expert writers as expressions of criticality in the literature reviews. A concordance analysis was later used to examine each occurrence of the linguistic devices within a broader context.

\subsection{Sampling Method}

A purposive sampling technique was used in this study to develop two sets of corpora. The reference corpus, ELRC, consists of research articles published in the year 2019 from peer reviewed, high-ranking linguistics and applied linguistics journals. Following Lee and Chen (2009), these writers were considered "expert writers" on the ground that these papers were published in renowned and top journals in the field. Furthermore, these papers had been through a rigorous proof-reading, peer review, and editorial process and taken to be good models of writing to which student writers can aspire (Lee \& Chen, 2009).

The journals, English for Academic Purposes, Language and Communication and Applied Linguistics were selected from different publishers where the topics were randomly picked. In most texts, literature review was embedded within the Introduction and was not identified as a separate subsection of it. Therefore, only texts with separated literature review sections were used for the purpose of the current study since it was easier to identify the literature review. After thorough evaluation, 62 literature review sections from the three (3) journals were selected and downloaded. As a reference corpus, ELRC needed to have a greater number of words as compared to the studied corpus. This explains the size of the corpus. Table 2 presents a detailed description of ELRC in this study. 
Muna Liyana Mohamad Tarmizi, Anealka Aziz Hussin

Expressions of Criticality in Expert and Student Writing: A Corpus Contrastive Analysis of Literature Reviews

Table 2: Expert Literature Review Corpus Word Count

\begin{tabular}{lll}
\hline & Number of Texts & Number or Words \\
\hline English for Academic Purposes & 20 & 30150 \\
Language and Communication & 21 & 37331 \\
Applied Linguistics & 21 & 36868 \\
\hline Total Number of Text / Word Count & 62 & 104349 \\
\hline
\end{tabular}

The target corpus, Malaysian Literature Review Corpus (MLRC), consists of literature review chapters from UiTM applied linguistics master theses. The applied linguistics master theses were selected based on several factors:

a. The applied linguistics master theses should be written by Malaysian student writers

b. The applied linguistics master theses were accessible and available at UiTM's postgraduate office (Institut Pengajian Siswazah, IPSis)

c. The applied linguistics master theses were available in a period of time which was determined to be from January 2013 to December 2019

Since the number of graduating students from UiTM Applied Linguistics Master program is unstable, and in one-year time, there was only a minimal number of one student graduating, the MLRC corpus needed to be developed by collecting literature review chapter from UiTM applied linguistics master theses available since the year 2013 to 2019 to have a comparable number of word count for data analysis purposes. After careful evaluation, eight (8) applied linguistics master theses which reflected the above-mentioned criteria were selected. Table 3 presents a description of MLRC used for this study.

Table 3: Malaysian Literature Review Corpus Word Count

\begin{tabular}{lll}
\hline Theses & Number of texts & Number or Words \\
\hline Language Acquisition & 1 & 11786 \\
Technology in Language Teaching & 1 & 10670 \\
Professional Communication & 5 & 44665 \\
Genre Analysis & 1 & 13566 \\
\hline Total Number of Texts / Word Count & 8 & 80687 \\
\hline
\end{tabular}

\subsection{Research Instrument}

Four (4) writers-oriented features proposed by Hyland's (2005) Academic Interaction model known as stance were used in this study to identify the most common expressions of criticality used by student and expert writers. A list of words for the four (4) features of stance i.e., hedges, boosters, attitude markers and self-mention was adopted from Dobakhti (2012) as the research instrument. WordSmith Tools was also used to analyze the samples. Two functions from the said software namely detailed consistency analysis and concordance were applied to identify the most common linguistic devices used by expert writers and student 
writers as expressions of criticality in the literature reviews and to show the examples how the expressions of criticality were used in their contexts.

\subsection{Data Collection}

Based on the stated criteria in selecting the literature reviews for student writers in the Sampling Method section, eight (8) literature reviews accessible and available at UiTM's postgraduate office (Institut Pengajian Siswazah, IPSis) were collected in soft-copy form from the CDs. The literature reviews were then renamed and saved in txt format. For the expert writers, 62 literature reviews found in the selected three high-ranking linguistics and applied linguistics journals (e.g., English for Academic Purposes, Language and Communication and Applied Linguistics) were downloaded in online form from UiTM electronic database before they were renamed and saved in txt format. All texts were cleaned of tables, figures, headers, footers, diagrams, images as well as references to ensure smooth and accurate data processing.

\subsection{Data Analysis}

Wordlists for hedges, boosters, attitude markers, self-mentions and literature reviews for both expert writers and student writers were generated using Wordsmith Tools. Wordlists can tell a list of words in a text as well as the frequency of each word found. These wordlists were used in detailed consistency analysis to show the number of texts each word occurred to determine the most common linguistic devices from the four (4) features of stance used by expert writers and student writers as expressions of criticality in the literature reviews. The Total column shows how many instances of each word occurred overall, whereas Texts shows how many text-files it came in. Based on Figure 1, self-mention 'we' occurred 152 times and was found in 42 texts.

Figure 1: Detailed Consistency Analysis for Self-Mentions

W self M JA consistency(4_files)17091638.Ist

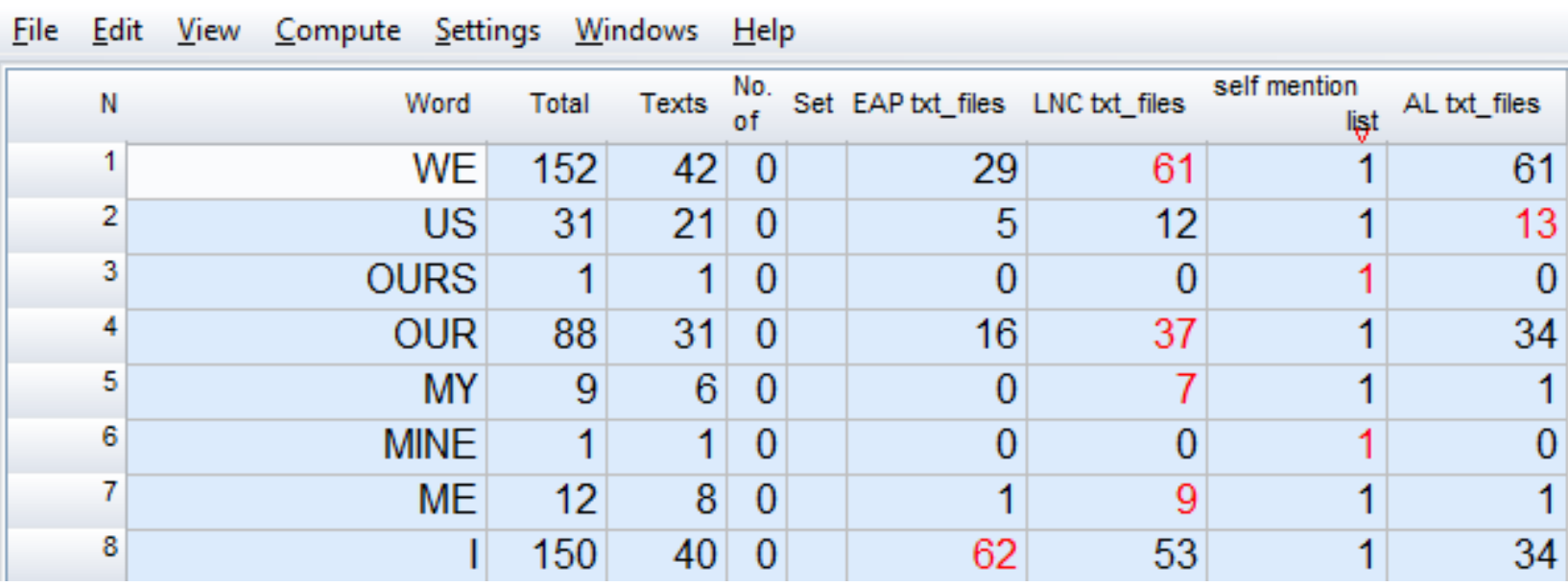


Muna Liyana Mohamad Tarmizi, Anealka Aziz Hussin

Expressions of Criticality in Expert and Student Writing: A Corpus Contrastive Analysis of Literature Reviews Once the most common linguistic devices words used to express criticality were determined, concordance analysis was carried out. A concordance analysis was used to examine each occurrence of the most common linguistic devices within a broader context.

Figure 2: Concordance Analysis for Self-Mentions 'we'

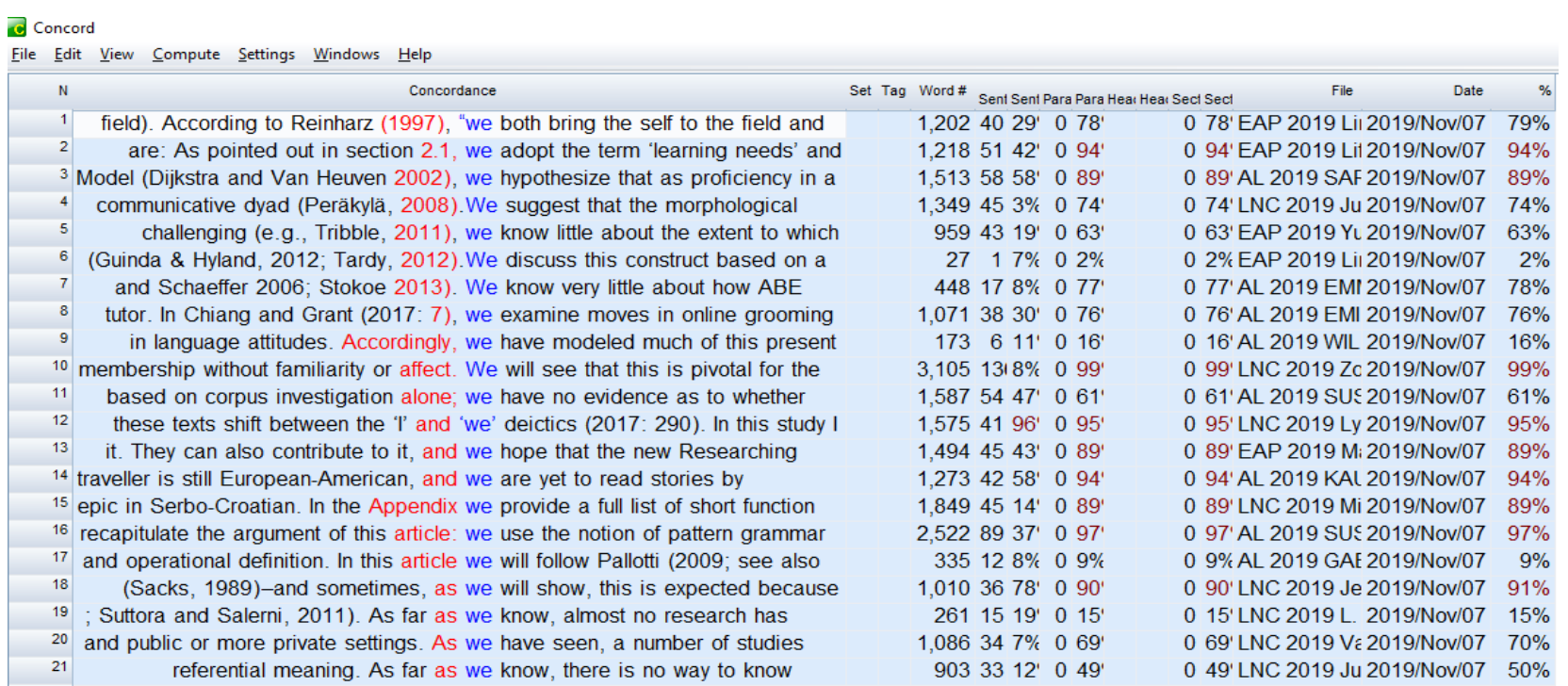

Based on Figure 2, contexts, and examples on how writers used self-mention ' $w e$ ' can be clearly seen for further analysis. When examining the concordance lines, irrelevant examples, i.e., those occurrences of the words not used to express criticality were sifted out such as 'could' in example (1):

(1) From the analysis of graphics, it could be seen that images of hardware product frequently seen in the corporate websites and the top, bottom and the body of the webpage contained graphics with text (Medina et al.,

2005). (UiTM 1)

Excerpts from the two corpora were selected to serve as examples as well as to examine the similarities and differences of how learners and experts used expressions of criticality in writing the literature review.

\subsection{Findings and Discussions}

The findings in this study are discussed based on the four stance features in Hyland (2005) Academic Interaction modal. The frequency of occurrences of expressions of criticality found in expert and student writings are explained in terms of hedges, boosters, attitude markers and self-mentions. Since the total number of words for both corpora are not same whereby ELRC, as the reference corpus has a larger total number of Copyright (C) The Author(s). All Rights Reserved 
words (104,349 words) as compared to MLRC (80,687 words), the frequency of occurrence for linguistic devices which are used to express criticality in both corpora were normalized per 1,000 words. To calculate a normalized frequency, the frequency for each linguistic device found in each corpus was divided with the total number of words for that corpus and then it is multiplied with the normalizing factor, in this case, 1,000. For example, the word can was found 224 times in 80,687 words, when the number is normalized to 1,000, the frequency for can is 2.77 per 1,000 words.

This section starts with explanation on the overall findings on the four features used by expert writers and student writers to express criticality. This follows by discussion on each feature (hedges, boosters, attitude markers and self-mentions) used by the two groups of writers with specification on the types of linguistic devices used to express criticality as well as their frequency of occurrences normalized per thousand words. Finally, comparisons are made on the similarities and differences on how expert writers and student writers express criticality when reviewing the literature.

\subsection{Overall findings}

The overall findings indicate that student writers and expert writers use a range of linguistic devices in hedging, boosting, attitude markers, and self-mentions strategies to express criticality when reviewing the literature. The frequency of occurrences per thousand words of these stance features in both student and expert writing are illustrated in Table 4.

Table 4: Overall Frequency of Hedges, Boosters, Attitude Markers and Self-Mentions per 1000 Words

\begin{tabular}{lcc}
\hline & MLRC & ELRC \\
Hedges & 22.9 & 22.4 \\
Boosters & 14.3 & 16.75 \\
Attitude Markers & 9.93 & 10.0 \\
Self-Mentions & 2.5 & 4.25 \\
\hline
\end{tabular}

The frequency of occurrence of hedges in MLRC is 22.9 per thousand words. While boosters, attitude markers, and self-mentions are 14.3, 9.93, and 2.5 per thousand words, respectively. For ELRC, the frequency of occurrence of hedges, boosters, attitude markers, and self-mentions is $22.4,16.75,10.0$, and 4.25 per thousand words. In general, expert writers displayed the use of more expressions of criticality when reviewing the literature Furthermore, hedges were used most by both student and expert writers in expressing criticality followed by boosters, attitude markers, and self-mentions.

\subsection{Expressions of Criticality Used by Expert Writers in ELRC}

\section{Hedges}


Muna Liyana Mohamad Tarmizi, Anealka Aziz Hussin

Expressions of Criticality in Expert and Student Writing: A Corpus Contrastive Analysis of Literature Reviews

Hedging strategy has been applied more frequently as compared to other strategies in expressing criticality by expert writers.

Table 5: List of Linguistic Devices Used by Expert Writers in Hedging Strategy to Express Criticality

\begin{tabular}{|c|c|c|c|}
\hline & EAP & LNC & $\mathbf{A L}$ \\
\hline $\mathbf{C A N}$ & 0.54 & 1.05 & 0.72 \\
\hline MAY & 0.35 & 0.70 & 0.68 \\
\hline MOST & 0.47 & 0.39 & 0.50 \\
\hline ABOUT & 0.20 & 0.43 & 0.49 \\
\hline SOME & 0.28 & 0.44 & 0.38 \\
\hline OFTEN & 0.24 & 0.34 & 0.26 \\
\hline WOULD & 0.09 & 0.30 & 0.33 \\
\hline RATHER & 0.12 & 0.23 & 0.24 \\
\hline COULD & 0.19 & 0.25 & 0.14 \\
\hline GENERAL & 0.17 & 0.13 & 0.25 \\
\hline TEND & 0.20 & 0.13 & 0.13 \\
\hline ACCORDING & 0.16 & 0.22 & 0.07 \\
\hline SEVERAL & 0.15 & 0.11 & 0.17 \\
\hline CERTAIN & 0.11 & 0.18 & 0.09 \\
\hline MIGHT & 0.12 & 0.09 & 0.18 \\
\hline POINT & 0.08 & 0.12 & 0.18 \\
\hline FEW & 0.10 & 0.10 & 0.16 \\
\hline TYPICALLY & 0.09 & 0.13 & 0.11 \\
\hline SEEN & 0.06 & 0.20 & 0.08 \\
\hline LITTLE & 0.13 & 0.08 & 0.13 \\
\hline LIKELY & 0.15 & 0.09 & 0.10 \\
\hline GENERALLY & 0.11 & 0.11 & 0.11 \\
\hline ARGUE & 0.16 & 0.09 & 0.08 \\
\hline POSSIBLE & 0.08 & 0.10 & 0.14 \\
\hline USUALLY & 0.04 & 0.19 & 0.05 \\
\hline SUGGEST & 0.16 & 0.05 & 0.07 \\
\hline FREQUENTLY & 0.09 & 0.11 & 0.07 \\
\hline EXTENT & 0.13 & 0.04 & 0.08 \\
\hline ALWAYS & 0.01 & 0.13 & 0.08 \\
\hline INDICATE & 0.11 & 0.09 & 0.02 \\
\hline TYPICAL & 0.02 & 0.11 & 0.06 \\
\hline LARGELY & 0.05 & 0.05 & 0.09 \\
\hline ARGUMENT & 0.09 & 0.06 & 0.04 \\
\hline APPEAR & 0.03 & 0.06 & 0.10 \\
\hline
\end{tabular}

Based on Table 5, it can be observed that expert writers used linguistic devices like modal verbs can, may, would, and could with different frequency. Expert writers too, used approximators (about, some, often, several, few, generally, typically) more frequently other than introductory verbs (indicate, suggest, appear) and probability adjectives (possible). Modal verb can was used by expert writers in coming up with claims or propositions as well as to report or summarize key findings from the previous studies which were relevant to their topic.

1. Thus, their variable use across tasks of structures that are more or less difficult for L2 acquirers can be said to be primarily due to the tasks themselves, rather than to the participants' (in)competences. ( $A L G$ ) 
2. From several studies, it can be observed that polite behaviour correlates with 'considerate', 'friendly' or 'kind' in different varieties of English, while Japanese speakers tend to associate politeness not only with honorifics, but also with modesty and 'humble', 'reserved' or 'discreet' behaviour (Ide et al., 1992; Obana and Tomoda, 1994; Pizziconi, 2007). (LNCV)

Adverbs such as likely was used to reduce complete commitment on statements or claims made. This does not necessarily indicate uncertainty, rather could be a more accurate way to provide argument and evaluation.

3. While this may be a valid method of identifying lexical bundles for high-proficiency speakers, especially those living in first language (L1) environments, it is likely that lower proficiency speakers in EFL contexts where input is mainly limited to classroom study will have a different experience of the L2

\section{Boosters}

Boosting strategy was used by expert writers to express criticality. Based on Table 6 , it can be seen that adverbs like more, indeed, very and reporting verbs like found, showed, shows, demonstrate, do, and does were used by expert writers more frequently as compared to other linguistic devices.

Table 6: List of Linguistic Devices Used by Expert Writers in Boosting Strategy to Express Criticality

\begin{tabular}{lccc}
\hline & EAP & LNC & AL \\
MORE & 1.09 & 1.00 & 1.56 \\
FOUND & 0.80 & 0.32 & 0.91 \\
ONLY & 0.20 & 0.44 & 0.52 \\
DO & 0.15 & 0.26 & 0.20 \\
DOES & 0.06 & 0.38 & 0.22 \\
SHOULD & 0.13 & 0.26 & 0.18 \\
VERY & 0.09 & 0.25 & 0.31 \\
EVIDENCE & 0.06 & 0.11 & 0.24 \\
SHOWED & 0.09 & 0.08 & 0.12 \\
PARTICULARLY & 0.18 & 0.09 & 0.09 \\
CERTAIN & 0.11 & 0.18 & 0.18 \\
SHOW & 0.08 & 0.10 & 0.15 \\
KNOWN & 0.07 & 0.10 & 0.15 \\
WITHOUT & 0.05 & 0.11 & 0.13 \\
CLEAR & 0.09 & 0.05 & 0.09 \\
HIGHLY & 0.12 & 0.06 & 0.16 \\
DEMONSTRATED & 0.05 & 0.05 & 0.10 \\
COURSE & 0.13 & 0.03 & 0.13 \\
INDEED & 0.05 & 0.07 & 0.08 \\
FIND & 0.11 & 0.05 & 0.10 \\
MUST & 0.02 & 0.11 & 0.08 \\
ALWAYS & 0.01 & 0.13 & 0.11 \\
SIGNIFICANTLY & 0.07 & 0.03 & 0.10 \\
CLEARLY & 0.04 & 0.05 & \\
\hline
\end{tabular}


Muna Liyana Mohamad Tarmizi, Anealka Aziz Hussin

Expressions of Criticality in Expert and Student Writing: A Corpus Contrastive Analysis of Literature Reviews

Expert writers have a great tendency to present their argument with assurance through the use of 'do' and 'does' in literature review writing.

1. A second methodological issue is that most of this research assumed, rather than demonstrated, that changes along these task dimensions $d o$ indeed bring about higher cognitive demands, that is, more difficulty. ( $A L G$ )

2. Yet, their narratives do not always adhere to simple Orientalist narratives, as is shown in Part 4. (AL $K$ )

3. While visual world studies provide evidence that predictive behaviors do take place, one shortcoming of this type of study compared to real-world processing is the limited number of items from which one has to predict. (LNC D)

\section{Attitude Markers}

In terms of attitude markers, expert writers used adjectives like only, important, complex, even, and like to critically evaluate their opinions, attitudes and feelings.

Table 7: List of Linguistic Devices Used by Expert Writers in Attitude Markers Strategy to Express Criticality

\begin{tabular}{|c|c|c|c|}
\hline & EAP & LNC & $\mathbf{A L}$ \\
\hline ONLY & 0.20 & 0.44 & 0.52 \\
\hline IMPORTANT & 0.37 & 0.16 & 0.36 \\
\hline COMPLEX & 0.20 & 0.10 & 0.49 \\
\hline SHOULD & 0.13 & 0.26 & 0.22 \\
\hline EVEN & 0.14 & 0.22 & 0.18 \\
\hline LIKE & 0.11 & 0.23 & 0.17 \\
\hline SIGNIFICANT & 0.15 & 0.08 & 0.29 \\
\hline DIFFICULT & 0.07 & 0.05 & 0.30 \\
\hline MAIN & 0.12 & 0.16 & 0.06 \\
\hline CRITICAL & 0.06 & 0.20 & 0.04 \\
\hline KEY & 0.04 & 0.11 & 0.12 \\
\hline BETTER & 0.07 & 0.04 & 0.15 \\
\hline MUST & 0.02 & 0.12 & 0.10 \\
\hline MAJOR & 0.09 & 0.06 & 0.06 \\
\hline INTERESTING & 0.09 & 0.06 & 0.04 \\
\hline EXPECTED & 0.05 & 0.07 & 0.07 \\
\hline BEST & 0.04 & 0.06 & 0.09 \\
\hline APPROPRIATE & 0.11 & 0.04 & 0.04 \\
\hline CONSISTENT & 0.04 & 0.05 & 0.09 \\
\hline USEFUL & 0.09 & 0.01 & 0.07 \\
\hline UNIQUE & 0.05 & 0.03 & 0.08 \\
\hline CRUCIAL & 0.02 & 0.11 & 0.03 \\
\hline PREFERRED & 0.10 & 0.01 & 0.03 \\
\hline ESSENTIAL & 0.03 & 0.07 & 0.04 \\
\hline NECESSARY & 0.05 & 0.03 & 0.03 \\
\hline MEANINGFUL & 0.02 & 0.02 & 0.07 \\
\hline IMPORTANTLY & 0.01 & 0.04 & 0.06 \\
\hline NECESSARILY & 0.03 & 0.07 & 0 \\
\hline
\end{tabular}


Based on Table 7, it can be observed that expert writers include both positive and negative adjectives to provide their personal and professional attitude, opinion, and feelings about certain propositions through the frequent use of words like difficult, even, interesting, and significant.

1. Through an analysis of introductions of published journal articles from a diverse range of disciplines, they presented a complex classification system of reporting verbs. (EAP P)

2. Thus, without support, it appears the research publication process presents even greater challenges to the EAP practitioner $(E A P M)$

\section{Self-Mentions}

Self-mentions is another strategy used by expert writers to express criticality. Personal pronouns and possessive adjectives such as we, I, our, us, and me were frequently used by expert writers when reviewing the literature.

Table 8: List of Linguistic Devices Used by Expert Writers in Self Mentions Strategy to Express Criticality

\begin{tabular}{lccc}
\hline & EAP & LNC & AL \\
WE & 0.28 & 0.58 & 0.58 \\
I & 0.59 & 0.51 & 0.33 \\
OUR & 0.15 & 0.35 & 0.33 \\
US & 0.05 & 0.11 & 0.12 \\
ME & 0.01 & 0.09 & 0.01 \\
MY & 0 & 0.07 & 0.01 \\
\hline
\end{tabular}

Expert writers used we most frequently as self-mention strategy to highlight their role in the research or in highlighting the phenomenon being discussed. For examples:

1. We know very little about how ABE guidance is deployed in real-time interviews, and whether it hinders or facilitates evidence-giving in cases of sexual assault. $(A L E)$

2. As far as we know, almost no research has been performed that compared the speech of parents to infants according to their children's linguistic stage. $(A L A B)$

3. Taking these aspects into consideration, we agree that voice is "an integral aspect of self-representation in academic discourse" (Hyland, 2008, p. 20), representing the writers' multiple selves, their ideas, and the relationships with the readers within and beyond the discipline. $(A L S)$

\subsection{Expressions of Criticality Used by Student Writers in MLRC}

\section{Hedges}

Student writers use hedges to express criticality more frequently as compared to other strategies. The following table shows the various types of linguistic devices applied by eight student writers in hedging strategy. These linguistic devices occurred more than ten times in the MLRC corpus, and the frequency of 
Muna Liyana Mohamad Tarmizi, Anealka Aziz Hussin

Expressions of Criticality in Expert and Student Writing: A Corpus Contrastive Analysis of Literature Reviews occurrences were normalized per thousand words. Based on Table 9, it can be seen that student writers used modal verbs like can, may, could, and might more often to express criticality. Other than that, approximators such as about, few, generally, frequently, mainly, commonly, almost, and mostly were also found in MLRC as well as adjectives as in likely, and introductory verbs like indicate and appear.

Table 9: List of Linguistic Devices Used by Student Writers in Hedging Strategy to Express Criticality

\begin{tabular}{lllllllll}
\hline & Thesis 1 & Thesis 2 & Thesis 3 & Thesis 4 & Thesis 5 & Thesis 6 & Thesis 7 & Thesis 8 \\
CAN & 0.62 & 0.09 & 0.82 & 0.61 & 0.17 & 0.04 & 0.05 & 0.02 \\
MAY & 0.11 & 0.05 & 0.06 & 0.35 & 0.12 & 0.12 & 0.15 & 0 \\
MOST & 0.12 & 0.24 & 0.04 & 0.17 & 0.20 & 0.35 & 0.06 & 0.14 \\
ABOUT & 0.07 & 0.06 & 0.05 & 0.04 & 0.14 & 0.12 & 0 & 0.07 \\
OFTEN & 0.12 & 0.06 & 0.04 & 0.02 & 0.01 & 0.06 & 0.02 & 0.02 \\
COULD & 0.11 & 0.11 & 0.02 & 0 & 0.05 & 0.31 & 0.02 & 1.62 \\
ACCORDING & 0.43 & 0.01 & 0.31 & 0.10 & 0.10 & 0.20 & 0.05 & 0.11 \\
MIGHT & 0.02 & 0 & 0 & 0.07 & 0.01 & 0.07 & 0.02 & 0.07 \\
POINT & 0.02 & 0.01 & 0 & 0.04 & 0.05 & 0.09 & 0.01 & 0 \\
CERTAIN & 0.05 & 0.07 & 0.07 & 0.01 & 0.05 & 0.05 & 0 & 0.10 \\
FEW & 0.01 & 0 & 0.02 & 0.04 & 0.04 & 0.04 & 0.01 & 0.06 \\
GENERALLY & 0.07 & 0 & 0.06 & 0.04 & 0 & 0.04 & 0.04 & 0.02 \\
LIKELY & 0.06 & 0.05 & 0.01 & 0.01 & 0.01 & 0.01 & 0 & 0.02 \\
LITTLE & 0.04 & 0.05 & 0 & 0.01 & 0.01 & 0.04 & 0 & 0.01 \\
FREQUENTLY & 0.04 & 0.05 & 0 & 0.01 & 0.05 & 0.14 & 0 & 0.01 \\
INDICATE & 0.04 & 0.04 & 0.01 & 0.05 & 0.04 & 0.04 & 0 & 0.01 \\
APPEAR & 0 & 0 & 0 & 0.02 & 0.01 & 0.07 & 0 & 0.01 \\
MAINLY & 0.01 & 0 & 0 & 0.05 & 0.06 & 0.01 & 0 & 0.01 \\
AROUND & 0.01 & 0 & 0.02 & 0.01 & 0 & 0 & 0 & 0 \\
COMMONLY & 0.02 & 0.05 & 0 & 0.02 & 0.02 & 0.01 & 0.01 & 0 \\
ALMOST & 0.01 & 0.04 & 0 & 0.04 & 0.02 & 0.05 & 0 & 0.02 \\
MOSTLY & 0 & 0.04 & 0 & 0 & 0.01 & 0.01 & 0 & 0.07 \\
\hline
\end{tabular}

Modal verb can has the highest frequency of occurrence MLRC whereby this expression was used passively to highlight a research gap or issue as illustrated in the following example:

1. It can be said that not many studies have been conducted in the matter of English prosody utilization in Malaysian context. (Thesis 4)

Furthermore, can is also used when writers report or summarize key findings from the previous studies which are related to their topic.

2. This is because, Nikitina (2011) believed that video recording of the casting activities can help to improve proficiency acquired through the memorization of important speeches, role play and also the setup of the acting script. (Thesis 3)

It is also noteworthy that student writers used reporting verb according 106 times (1.31 per thousand words) which is two times higher than expert writers (47 times).

3. According to Kruti and Alan (2009), influential promotion is aimed to persuade and convince individuals to make a purchase. (Thesis 1 ) 
International Journal of Modern Languages and Applied Linguistics

e-ISSN: 2600-7266

4. According to Kalajahi (2012), acquiring vocabulary had received much attention since second language and foreign language learners had problems in developing their vocabulary bank. (Thesis 8 )

5. According to Galin et al. (2004), face-to-face communication has been found to be an excellent medium in negotiation. (Thesis 7)

\section{Boosters}

Boosting strategy has been applied widely too by student writers when expressing criticality in literature review. Table 10 illustrates the various types of linguistic devices and their normalized frequency used by student writers in boosting strategy. The most common boosters used to express criticality in MLRC comprise more, found, should, showed, and without. For boosters, learners or student writers tend to use expressions like 'showed' when summarizing previous work and when indicating a gap in previous studies.

Table 10: List of Linguistic Devices Used by Student Writers in Boosting Strategy to Express Criticality

\begin{tabular}{ccccccccc}
\hline & Thesis 1 & Thesis 2 & Thesis 3 & Thesis 4 & Thesis 5 & Thesis 6 & Thesis 7 & Thesis 8 \\
MORE & 0.37 & 0.50 & 0.27 & 0.06 & 0.26 & 0.38 & 0.19 & 0.76 \\
FOUND & 0.09 & 0.63 & 0.24 & 0.10 & 0.09 & 0.30 & 0.07 & 0.32 \\
DO & 0 & 0.06 & 0.06 & 0.02 & 0.24 & 0.06 & 0 & 0.05 \\
DOES & 0.01 & 0 & 0.01 & 0.05 & 0 & 0.01 & 0 & 0 \\
SHOULD & 0.26 & 0.05 & 0.25 & 0.20 & 0.09 & 0.06 & 0 & 0.15 \\
VERY & 0.05 & 0.05 & 0.02 & 0.11 & 0.10 & 10 & 0.01 & 0 \\
EVIDENCE & 0 & 0.04 & 0 & 0 & 0 & 0.02 & 0.01 & 0 \\
SHOWED & 0.02 & 0.25 & 0.15 & 0 & 0.09 & 0.21 & 0 & 0.15 \\
PARTICULARLY & 0.01 & 0 & 0.01 & 0 & 0.02 & 0.04 & 0 & 0 \\
CERTAIN & 0.05 & 0.07 & 0.07 & 0.01 & 0.05 & 0.05 & 0 & 0.10 \\
SHOW & 0.07 & 0.02 & 0 & 0 & 0.15 & 0.11 & 0 & 0.02 \\
KNOWN & 0.09 & 0.14 & 0.04 & 0.02 & 0.04 & 0 & 0 & 0.01 \\
WITHOUT & 0.02 & 0.02 & 0.09 & 0.02 & 0.02 & 0.02 & 0.01 & 0.32 \\
FACT & 0.09 & 0.09 & 0 & 0.01 & 0.02 & 0.02 & 0 & 0.01 \\
HIGHLY & 0.04 & 0.01 & 0 & 0 & 0.04 & 0.01 & 0 & 0.01 \\
CLEAR & 0.01 & 0.01 & 0.05 & 0.02 & 0.12 & 0.04 & 0.01 & 0 \\
DEMONSTRATED & 0.04 & 0.01 & 0.01 & 0 & 0 & 0 & 0 & 0 \\
COURSE & 0 & 0.06 & 0.01 & 0.01 & 0.01 & 0.02 & 0 & 0 \\
INDEED & 0.04 & 0 & 0 & 0 & 0 & 0 & 0 & 0 \\
FIND & 0.04 & 0.07 & 0 & 0.05 & 0.05 & 0.04 & 0.01 & 0.05 \\
MUST & 0.01 & 0.04 & 0.21 & 0.04 & 0.02 & 0.07 & 0 & 0.01 \\
ALWAYS & 0.01 & 0 & 0.02 & 0 & 0.02 & 0.01 & 0.01 & 0.04 \\
SHOWS & 0.02 & 0.01 & 0.02 & 0.05 & 0.01 & 0.01 & 0.01 & 0 \\
CLEARLY & 0.02 & 0.01 & 0.05 & 0 & 0.06 & 0.07 & 0 & 0 \\
KNOW & 0 & 0 & 0 & 0.02 & 0.02 & 0.04 & 0 & 0.06 \\
\hline & & & & & & & 0 & 0
\end{tabular}

Other than approximators like more, student writers had a tendency to use reporting verbs such as showed, found, show, and find as boosters which suggests that emphasis was given to highlight on findings from previous studies rather than stressing on the strengths or weaknesses of the evaluated studies.

1. His analysis showed that there were certain phrases that were not being translated in subtitles. (Thesis 8 )

2. The findings showed that this site gets good responses from the users and positive perception in the efforts to improve the prototype. (Thesis 3) 
Muna Liyana Mohamad Tarmizi, Anealka Aziz Hussin

Expressions of Criticality in Expert and Student Writing: A Corpus Contrastive Analysis of Literature Reviews 3. This showed that pragmalinguistic problems arose for Japanese producing English Complaints, especially when talking to the Professor. (Thesis 6)

\section{Attitude Markers}

Attitude marker strategy was also used by student writers in expressing criticality. Based on Table 11, various types of adjectives were applied when student writers provide their evaluation in terms of personal or professional opinions, emotions, and attitudes towards certain claims or propositions.

Table 11: List of Linguistic Devices Used by Student Writers in Attitude Markers Strategy to Express Criticality

\begin{tabular}{lcccccccc}
\hline & Thesis 1 & Thesis 2 & Thesis 3 & Thesis 4 & Thesis 5 & Thesis 6 & Thesis 7 & Thesis 8 \\
ONLY & 0.17 & 0.12 & 0.17 & 0.19 & 0.12 & 0.07 & 0.05 & 0.27 \\
IMPORTANT & 0.15 & 0.15 & 0.14 & 0.27 & 0.12 & 0.21 & 0.01 & 0.11 \\
COMPLEX & 0.01 & 0.02 & 0.01 & 0 & 0 & 0.02 & 0 & 0 \\
EVEN & 0.04 & 0.02 & 0.01 & 0.11 & 0.05 & 0.06 & 0 & 0.12 \\
LIKE & 0.04 & 0.04 & 0.05 & 0.02 & 0.04 & 0.04 & 0.06 & 0.06 \\
SIGNIFICANT & 0.20 & 0.09 & 0.01 & 0.02 & 0.09 & 0.06 & 0.05 & 0.11 \\
DIFFICULT & 0.01 & 0.01 & 0.04 & 0.05 & 0 & 0.01 & 0.01 & 0.01 \\
MAIN & 0.17 & 0.05 & 0.04 & 0.01 & 0.11 & 0.21 & 0.01 & 0.11 \\
CRITICAL & 0.04 & 0 & 0 & 0 & 0 & 0.01 & 0 & 0 \\
KEY & 0.09 & 0.01 & 0.01 & 0 & 0.01 & 0.01 & 0 & 0 \\
BETTER & 0.04 & 0.06 & 0.02 & 0.09 & 0.01 & 0.01 & 0.06 & 0.21 \\
MUST & 0.01 & 0.04 & 0.21 & 0.04 & 0.02 & 0.07 & 0 & 0.01 \\
MAJOR & 0.04 & 0.02 & 0.01 & 0.09 & 0 & 0.05 & 0 & 0.04 \\
INTERESTING & 0.04 & 0.04 & 0.01 & 0.02 & 0 & 0.02 & 0 & 0.02 \\
EXPECTED & 0.02 & 0 & 0 & 0.01 & 0.01 & 0.06 & 0 & 0 \\
BEST & 0.04 & 0.02 & 0 & 0.01 & 0 & 0.01 & 0.02 & 0.09 \\
APPROPRIATE & 0 & 0.01 & 0.20 & 0 & 0 & 0.04 & 0.01 & 0.01 \\
CONSISTENT & 0 & 0.01 & 0 & 0 & 0.01 & 0 & 0 & 0 \\
USEFUL & 0.02 & 0.07 & 0 & 0.02 & 0.01 & 0 & 0 & 0.02 \\
UNIQUE & 0.02 & 0.02 & 0 & 0.06 & 0 & 0.02 & 0 & 0 \\
CRUCIAL & 0.05 & 0 & 0 & 0.10 & 0 & 0.04 & 0 & 0.01 \\
PREFERRED & 0.06 & 0.01 & 0.04 & 0 & 0.06 & 0.14 & 0 & 0.07 \\
ESSENTIAL & 0.07 & 0 & 0 & 0.05 & 0.04 & 0.01 & 0 & 0.02 \\
\hline
\end{tabular}

Based on the table, it can be observed that student writers use adjectives which highlight positive views when expressing their personal or professional emotions and opinion about certain prepositions. Words like important, main, significant and better are used more frequently by learners as compared to expert writers.

1. Essentially, the term as described by dictionary.reference.com (2012) shows that second language is very important as a means of communication for speakers that have listeners of the same language. (Thesis 4)

2. Together these studies provide important insights into the significance of providing language options when advertising in the tourism industry. (Thesis 1 )

3. Only few research that were analysed by using qualitative method, which was interviewing participants. (Thesis 8) 
International Journal of Modern Languages and Applied Linguistics e-ISSN: 2600-7266

\section{Self-Mentions}

Personal pronouns and possessive adjectives are linguistic devices used as self-mentions strategy to express criticality. Words like we, I, our and my are the examples of personal pronouns and possessive adjectives found in MLRC.

Table 12: List of Linguistic Devices Used by Student Writers in Self-Mentions Strategy to Express Criticality

\begin{tabular}{lcccccccc}
\hline & Thesis 1 & Thesis 2 & Thesis 3 & Thesis 4 & Thesis 5 & Thesis 6 & Thesis 7 & Thesis 8 \\
WE & 0.02 & 0.05 & 0.06 & 0.02 & 0.04 & 0.02 & 0 & 0.01 \\
I & 0.07 & 0.20 & 0.06 & 0 & 0.40 & 0.63 & 0.04 & 0 \\
OUR & 0.01 & 0.04 & 0 & 0.01 & 0.02 & 0.04 & 0.01 & 0 \\
US & 0.05 & 0.01 & 0.01 & 0 & 0.01 & 0.07 & 0 & 0 \\
ME & 0 & 0.01 & 0 & 0.02 & 0.12 & 0.02 & 0 & 0 \\
MY & 0 & 0.02 & 0.09 & 0.02 & 0.10 & 0.04 & 0 & 0.01 \\
\hline
\end{tabular}

However, there are some instances where learners also use we as self-mentions strategy when presenting arguments or interpersonal information.

1. Based on the description by Edward M. Anthony, we can conclude that the approach should be based on the model or principles of the learning theory (Ahmad, 2011). (Thesis 3)

2. Lewis views this as raw database of readily combined chunks from which we can derive the patterning and we traditionally looked at this as the grammar rules (Lewis, 1993, p. 95).

(Thesis 2)

3. Katz and Fodor (1963) further discussed that we could see the proficiency of one's language by looking at his or her ability in using the language with correct grammar and rules. (Thesis 8 )

\subsection{Similarities and Differences on Expressions of Criticality Used by Student Writers and Expert Writers in Literature Review}

Student writers and expert writers used hedging strategies more frequently as compared to other strategies to express criticality in literature review writing. Modal verbs and approximators were often used by both groups of writers when stating certain claims or propositions to avoid absolute commitments as well as in providing precise evaluation. Through the use of hedges, the force of writers' claim can be reduced and thus could be a useful strategy to persuade readers to accept the proposition made by the writers.

1. Although L2 students generally expect WCF and are happy to receive it (Lee, 2008a), their positive attitudes may not translate into positive emotional experiences (McMartin-Miller, 2014). (EAP Y)

2. In general, it was clear that there seem to be different criteria reflecting variations for content and organization delineated by the researchers. (UiTM 5) 
Muna Liyana Mohamad Tarmizi, Anealka Aziz Hussin

Expressions of Criticality in Expert and Student Writing: A Corpus Contrastive Analysis of Literature Reviews

The study also discovered that student writers used reporting verbs 'according' two times more than expert writers. Excessive use of such a reporting verb made student writers' literature review writing sound like reporting rather than analyzing and synthesizing previous works critically. The lack of student writers' personal voice can be seen when they only use these linguistic devices to summarize other researchers' findings and interpretations rather than examining other important aspects of their research critically. The same issue has also been highlighted by Shahzavar and Kourepaz (2020) in their study where they mentioned that the poor performance in using critical thinking could be the reason why students could not provide justification or logical reasons in writing their theses.

Other than that, it was found that expert writers used boosters more frequently as compared to student writers. It seems that, when evaluating the literature, expert writers are more confident in exerting their critical stance through the use of boosters which reflect their certainty of knowledge. The emphasis made by expert writers through the use of words like do, does, clearly, particularly, and clear have increased the power of explanation and represented a strong claim about a state of affairs (Hyland, 1998). On the other hand, student writers used slightly less boosting strategy when reviewing the literature and appear to be more cautious when asserting certain claims and prepositions.

In a different finding, student writers tend to express their attitudes, opinions, or feelings on certain propositions and claims using positive evaluations. Whereas expert writers use a wider range of adjectives when providing their personal or professional evaluations as well as in highlighting issues and gaps of the current studies. Words like complex, difficult, essential, and crucial are used by expert writers to critically express their attitudinal stance about a state of affairs. Through the use of both positive and negative personal evaluation, expert writers managed to highlight the strengths and weaknesses of the reviewed studies critically.

On writer's presence, student writers do not extensively use self-mention like the first-person pronoun, $I$, in their thesis. They tend to downplay their personal role and highlight the phenomenon under research instead by referring to the current study more often through the use of phrases like 'this study' or the 'present study'. In some instances, student writers use the plural first-person pronoun we to engage with readers or to establish shared knowledge. For expert writers, they use first-person pronouns like we and $I$ to establish their role in the study (Hyland, 2005) as well as to state their original contribution to the field, and present their opinion (Walkova, 2019).

\subsection{CONCLUSION AND RECOMMENDATION}

The current study tried to identify the most common expressions of criticality used by student and expert writers in literature review sections. The findings showed that student writers could be more critical when evaluating literature through the use of a wider variety of linguistic devices like hedges, boosters, and attitude markers as shown by expert writers in their writings. Students too, need to observe the main purposes Copyright (C) The Author(s). All Rights Reserved 
of literature review, which include to evaluate, analyze, and synthesize the strengths and weaknesses of research as well as highlighting gaps in research to be able to produce critical evaluation and judgment. One of the limitations of this study is the corpus size; if the corpora had a bigger size, the results could be more representative. The current study could also be strengthened through triangulation, for example using the interview to gather a more holistic idea on the issue relates to students' use of critical expressions in literature review writing. The study identified some of the postgraduate students' problems in expressing criticality. The results may have some useful suggestions for supervisors in providing guidelines and instructions for the students to come up with more critical writing, especially in the literature review sections.

\section{References}

Ağçam, R. (2014). A Corpus-Based Study on Epistemic Adjectives in Academic English. American Journal of Educational Research, 2(12), 1230-1236. doi:10.12691/education-2-12-16

Akindele, O. (2008). A critical analysis of the literature review section of graduate dissertations at the University of Botswana. http://www.espworld. info/Articles_20/DOC/GRADUATE_WRITING_site.pdf

Anwardeen, N. H., Luyee, E. O., Gabriel, J. I., \& Kalajahi, S. A. (2013). An Analysis: The Usage of Metadiscourse in Argumentative Writing by Malaysian Tertiary Level of Students. English Language Teaching, 6(9). doi:10.5539/elt.v6n9p83

Barton, E. L. (1993). Evidentials, Argumentation, and Epistemological Stance. College English, 55(7), 745. doi: $10.2307 / 378428$

Biber, D. (2006). Stance in spoken and written university registers. Journal of English for Academic Purposes, 5(2), 97-116.

Biber, D., \& Finegan, E. (1989). Styles of stance in English: Lexical and grammatical marking of evidentiality and affect. Text - Interdisciplinary Journal for the Study of Discourse, 9(1). doi:10.1515/text.1.1989.9.1.93

Blagojević, Savka (2009) 'Expressing attitudes in academic research articles written by English and Serbian authors'. Linguistics and Literature 7 (1), 63-73

Bruce, I. (2014). Expressing criticality in the literature review in research article introductions in applied linguistics and psychology. English for Specific Purposes, 36, 85-96. doi:10.1016/j.esp.2014.06.004

Çakır, H. (2016). Native and Non-Native Writers' Use of Stance Adverbs in English Research Article Abstracts. Open Journal of Modern Linguistics, 06(02), 85-96. doi:10.4236/ojml.2016.62008

Chan, T. H. (2015). A corpus-based study of the expression of stance in dissertation acknowledgements. Journal of English for Academic Purposes, 20, 176-191. doi:10.1016/j.jeap.2015.09.005

Charles, M. (2006). The Construction of Stance in Reporting Clauses: A Cross-disciplinary Study of Theses. Applied Linguistics, 27(3), 492-518. doi:10.1093/applin/am1021

Crosthwaite, P., Cheung, L., \& Jiang, F. K. (2017). Writing with attitude: Stance expression in learner and professional dentistry research reports. English for specific purposes, 46, 107-123.

Leila, Dobakhti (2011) The discussion section of research articles in applied linguistics: Generic structure and stance features / Leila Dobakhti. $\mathrm{PhD}$ thesis, University of Malaya. 
Muna Liyana Mohamad Tarmizi, Anealka Aziz Hussin

Expressions of Criticality in Expert and Student Writing: A Corpus Contrastive Analysis of Literature Reviews

Escobar, C. C., \& Fernández, L. C. (2018). EFL Learners' Development of Voice In Academic Writing:

Lexical bundles, Boosters/Hedges and Stance-taking Strategies. GiST Education and Learning Research Journal, (15), 96-124. doi:10.26817/16925777.392

Fernandez, K. V. (2019). Critically Reviewing Literature: A Tutorial for New Researchers. Australasian Marketing Journal, 27(3), 187-196. https://doi.org/10.1016/j.ausmj.2019.05.001

Geng, Y., \& Wharton, S. (2016). Evaluative language in discussion sections of doctoral theses: Similarities and differences between L1 Chinese and L1 English writers. Journal of English for Academic Purposes, 22, 80-91. doi:10.1016/j.jeap.2016.01.001

Gray, B., Biber, D. (2012). Current conceptions of stance. In Hyland, K., Sancho Guinda, C. (Eds.), Stance and voice in written academic genres (pp. 15-33). New York, NY: Palgrave Macmillan.

Hart, C. (1998). Doing a literature review: Releasing the social science research imagination. London: Sage Publications.

Hei, K., \& David, M. (2015). Basic and Advanced Skills They Don't Have: The Case of Postgraduate and Literature Review Writing. Malaysian Journal Of Learning And Instruction, 12, 131-150. doi:10.32890/mjli2015.12.7

Hidalgo, H \& Funderburk Razo R. M. (2014), Writing the literature review: Two Maxican novice writers' challenges. Special Edition, Spanish-English writing in the Americas, 6, 38-55.

Hyland, K. (1998). Boosting, hedging and the negotiation of academic knowledge. Text - Interdisciplinary Journal for the Study of Discourse, 18(3). doi:10.1515/text.1.1998.18.3.349

Hyland, K. (2005). Stance and engagement: A model of interaction in academic discourse. Discourse Studies, 7(2), 173-192. doi:10.1177/1461445605050365

Hyland K., Diani G. (2009) Introduction: Academic Evaluation and Review Genres. In: Hyland K., Diani G. (eds) Academic Evaluation. Palgrave Macmillan, London. https://doi.org/10.1057/9780230244290_1

Jiang, F., \& Hyland, K. (2015). 'The fact that': Stance nouns in disciplinary writing. Discourse Studies, 17(5), 529-550. doi:10.1177/1461445615590719

Kwan, B. S. (2006). The schematic structure of literature reviews in doctoral theses of applied linguistics. English for Specific Purposes, 25(1), 30-55. doi:10.1016/j.esp.2005.06.001

Kwan, B. S., Chan, H., \& Lam, C. (2012). Evaluating prior scholarship in literature reviews of research articles: A comparative study of practices in two research paradigms. English for Specific Purposes, 31(3), 188-201. doi:10.1016/j.esp.2012.02.003

Martin, J.R. \& Rose,David.(2003). Working with Discourse: London \&New York: Continuum

Martin, J.R. \& White,P.R.R.(2005). The Language of Evaluation : Appraisal in English. London: Continuum

Lancaster, Z. (2016). Expressing stance in undergraduate writing: Discipline-specific and general qualities. Journal of English for Academic Purposes, 23, 16-30. doi:10.1016/j.jeap.2016.05.006

Lee, A. (1998). A troubleshooter's checklist for prospective authors derived from reviewers' critical feedback. Teaching and Teacher Education, 14(8), 887-890. doi:10.1016/s0742-051x(98)90000-2

Lee, D. Y., \& Chen, S. X. (2009). Making a bigger deal of the smaller words: Function words and other key items in research writing by Chinese learners. Journal of Second Language Writing, 18(4), 281-296.

Lee, Geok Imm and Wong, Bee Eng and Chan, Swee Heng and Abdullah, Mardziah Hayati (2014) Stancetaking using lexico-grammatical features in argumentative writing of Malaysian undergraduates. Journal of Language and Communication, 1 (2). pp. 111-122. ISSN 2289-649X 
Lorés-Sanz, R. (2011). The construction of the author's voice in academic writing: The interplay of cultural and disciplinary factors. Text \& Talk - An Interdisciplinary Journal of Language, Discourse \& Communication Studies, 31(2), 173-193. doi:10.1515/text.2011.008

Matsuda P.K., Jeffery J.V. (2012) Voice in Student Essays. In: Hyland K., Guinda C.S. (eds) Stance and Voice in Written Academic Genres. Palgrave Macmillan, London. https://doi.org/10.1057/9781137030825 10

Nelson, N., \& Castello, M. (2012). Academic writing and authorial voice. In M. Castelló, \& C. Donahue (Eds.), University writing: Selves and texts in academic societies (pp. 33-52). Bingley UK: Emerald.

Osman, H. (2012). Planning a Review of Literature. In Strategies for Academic Writing. Shah Alam: UPENA. Oteíza, Teresa. (2017). The appraisal framework and discourse analysis

Shahsavar. Z \& Kourepaz. H. (2020) Postgraduate students' difficulties in writing their theses literature review, Cogent Education, 7:1, DOI: 10.1080/2331186X.2020.1784620

Thompson, G. \& Hunston, Susan. (2000). Evaluation: An introduction. Evaluation in text: authorial stance and the construction of discourse. 1-27.

Tucker, P. (2003). Evaluation in the art-historical research article. Journal of English for Academic Purposes, 2(4), 291-312. doi:10.1016/s1475-1585(03)00047-x

Xie, J. (2016). Direct or indirect? Critical or uncritical? Evaluation in Chinese English-major MA thesis literature reviews. Journal of English for Academic Purposes, 23, 1-15. doi:10.1016/j.jeap.2016.05.001 